$(81,8 \%)$ tương tự như nghiên cứu của tác giả Trần Doãn Trung Cang[5]. Có 5/49 trường hợp có tình trạng viêm phù nề lưỡi gà sau phẩu thuật. Các trường hợp này chúng tôi cho nằm điều trị với kháng sinh, kháng viêm, khi bệnh nhân hết tình trạng phù nề thì xuất viện. Có 4/49 trường hợp có chảy máu sau phẫu thuật, chủ yếu chảy máu sớm mức độ nhẹ xử trí bằng cách cầm máu bằng bông cầu tẩm oxy già hoăc lấy cục máu đông. 2 trường hợp chảy máu muộn do bong giả mạc từ hố amiđan xử trí bằng cách đốt điện và nằm theo dõi, khi không còn tình trạng chảy máu hoặc hố amiđan giả mạc đều thì cho bệnh nhân ra viện.

4.5. Kết quả điêu trị khi ra viện và sau 3 tháng phẫu thuật. Bảng 6 cho thây kết quả điều trị tốt khá cao với $75,5 \%$ khi ra viện và 93,9\% sau 3 tháng.Kết quả điều trị ngủ ngáy bằng cắt amiđan và chỉnh hình màn hầu của Huỳnh Ngọc Luận đạt tốt chiếm 51,4\%, khá chiếm $36,4 \%$, trung bình và không cải thiện chiếm $6,1 \%$ [3]. Mitchell, R. B. cũng cho rằng phẫu thuật cắt amiđan điều trị ngủ ngáy đạt kết quả tốt khi nhóm mẫu có phẫu thuật này có cải thiện lớn về chất lượng cuộc sống, chất lượng giấc ngủ, hơn là với nhóm không phấu thuật.

\section{KẾT LUÂNN}

Viêm amidan quá phát độ II trở lên kèm theo tình trạng béo phì làm tăng tích tụ mõ vùng cạnh hầu, thay đổi cấu trúc giải phẫu xung quanh hầu hong sẽ làm hẹp eo họng, hẹp đường hô hấp gẩy nên tình trạng ngủ ngáy của người bệnh.
Phẫu thuật cắt amiđan sẽ làm rộng eo họng, rộng đường hô hấp và sẽ giúp bệnh nhân cải thiện tình trạng ngáy đáng kể.

\section{TÀI LIÊU THAM KHẢO}

1. Nguyễn Hữu Khôi (2015), Rối loan thở lúc ngủ, ngủ ngáy và ngưng thở lúc ngủ, Viểm họng VA và amiđan Nhà xuất bản Y học, tr. 32-36.

2. Đăng Vũ Thông và các cộng sự (2011), "Đánh giả hiệu quả điếu tri ngưng thở khi ngư do tắc nghẽn bằng thông khí app lực dương liên tục tại Bênh Viên Chợ Rẫy", Tap chí Y hoc Thành phố Hồ Chí Minh. Tập 15,(Phụ bản số 4), tr. 97-101.

3. Hoàng Gia Thịnh, Võ Hiếu Bình và Võ Quang Phúc (2003), "Điều trị bệnh ngáy bằng phẫu thuật chỉnh hình họng màn hâuu Hernandez", Tap chí Y học Thành phố Hồ Chí Minh. Tập 7,(Phụ bản số 1), tr. tr.111-114.

4. Huỳnh Ngoc Luân (2014), "Nghiên cứu đăc điểm lâm sàng và kết quả điêu trị ngảy bằng phẩu thuật chỉnh hình màn hầu kết hợp với cắt amiđan", Luân án chuyên khoa cấp II, Trường Đại học Y Dược Huế.

5. Trân Doãn Trung Cang (2017), "P̉hấu thuật chỉnh hình màn hầu trong điêu trị ngáy và ngưng thở lúc ngủ do hẹp eo họng bằng dao plasma", Luận án chuyên khoa cấp II, Trường Đại học Ý Khoa Pham Ngọc Thạch.

6. Dell'Aringa, A. R. , et al. (2005), "Histological analysis of tonsillectomy and adenoidectomy specimens--January 2001 to May 2003", Braz J Otorhinolaryngol. 71(1), pp. 18-22.

7. Phan Văn Dưng (2006), "Nghiên cứu đặc điểm lâm sàng và kết quả điều trị viêm mũi xoang man tính được phâ̂u thuật tại Huế", Luận án chuyển khoa cấp II, Trường Đ̇ại Học Y Dược Huế.

8. Nguyê̂n Trung Nghĩa (2017), "Đ̉ánh giá kết quả điểu trị phẫu thuật cắt amiđan và nạo V.A đồng thời ở trẻ em", Luận văn cao học, Trường Đại học Y Dược Huế.

\title{
ĐỊNH VỊ MẠCH XUYÊN Đô̂NG MẠCH MÔNG TRÊN QUA CẮT LỚP VI TÍNH 320 LÁT CẮT
}

\section{TÓM TẮT}

Mục tiêu: (1) Các kích thước mạch xuyên động mạch mông trên ở người Việt trưởng thành trênCLiVT 320 lát cắt, (2) Định vị mạch xuyên động mạch mông trên ra da trên CLVT 320 lát cắt. Phương pháp nghiên cứu: mô tả lâm sàng không nhóm chứng. Kết quả: Nhánh nông ĐM mông trên cho ra 4-5 mạch

*Đai hoc Y khoa Pham Ngoc Thạch

**Trướng Đai hoc Y Hà Nội

***Bênh viền Chơ Rẫy, TPHCM.

Chịu trách nhiệm chính: Trân Đăng Khoa

Email: khoatrandr@gmail.com

Ngày nhan bài: 31/7/2021

Ngày phản biên khoa hoc: 22/8/2021

Ngày duyệt bài: 20/9/2021
Trần Đăng Khoa*, Trần Thiết Sơn**, Lê Nguyễn Diên Minh***

xuyên cơ, chiều dài mạch xuyên từ nguyên uỷ đễn điêm ra da $6 \mathrm{~cm}$, đường kính mạch xuyên $1-1,5 \mathrm{~mm}$, đi vào da khá chếch. Kết luân: Các mach xuyên cơ có đường kính trên $1,5 \mathrm{~mm}$ đi vào da một góc chếch và tâp trung từ khoảng $2 / 5$ đến khoảng $3,5 / 5$ trên trục $x$ và trên trục y các mạch xuyên tập trung từ khoảng $2 / 5$ đến khoảng $2,5 / 5$. CLVT

Tứ khóa: Động mạch mông trên,mạch xuyên cơ,

\section{SUMMARY}

IDENTIFYING AND LOCATING PERFORATORS OF THE SUPERIOR

GLUTEAL ARTERY BY MSCT 320

Objectives: (1)To measure the dimensions of perforators of the superior gluteal artery in 
Vietnamese adults on MSCT 320, (2)To locate the superior gluteal artery perforators in Vietnamese adults on MSCT 320. Method: A cross-sectional clinical study. Results: Superficial branch of the superior gluteal artery give off 4-5 branches for muscular perforators, the length of the perforator is $6 \mathrm{~cm}$, diameter of the perforator is $1-1,5 \mathrm{~mm}$, perforators run to the skin in a quite oblique direction. Conclusion: Diameter of the perforator is $1-1,5 \mathrm{~mm}$ and perforators run to the skin in a quite oblique direction. This rectangle on the CT is more localized with the perforators located from the interval 2/5$3.5 / 5$ on the $x$-axis and on the $y$-axis from the interval 2/5-2.5/5.

Key words: Superior gluteal artery, muscular perforator, MSCT

\section{I. ĐẶT VẤN ĐỀ}

Loét cùng cụt là một bệnh lý phổ biến, thường gặp trên những bệnh nhân như chấn thương cột sống, tai biến mạch máu não, suy mòn bỏng. Trên thế giới có rất nhiêu phương pháp phòng ngừa loét tì đè, cũng như nhiều phương pháp điều trị triệt để như phẫu thuật che phủ vùng tổn thương ở cùng cụt bằng các vạt da cân, vạt da cơ mông lớn hay vạt tự do., trong đó vạt da nhánh xuyên động mạch mông trên được sử dụng dưới hình thức có cuống liền hoặc vạt tự do trong tạo hình để che phủ các tổn khuyêtiloét cùng cụt. Vạt được sử dụng dưới nhiều hình thức như vạt dồn đẩy, vạt xoay, do cung xoay lớn và độ dày của vạt đủ, nên bảo đảm được mục đích che phủ.Để sử dụng vat nhánh xuyên động mạch mông trên, các phẩu thuật viên nắm vững đường đi và vị trí phân bố ra da của các nhánh xuyên động mạch mông trên. Ở nước ngoài, các tác giả để xuất kẻ một đường nối từ gai chậu sau trên đến đỉnhxương cụt, và từ gai chậu sau trên đến đỉnh mấu chuyển lớn, ở trung điểm đường nối từ gai chậu sau trên đến đỉnhxương cưt kẻmộtđường nối từ điểm giữa đến mấu chuyển lớn, đánh dấu một điểm ở một phần ba trong của đường nối từ gai chậu sau trên đến mấu chuyển lớn, nhánh xuyên chính động mạch mông trên sẽ tìm thấy ở phần ngang và phần xa của điểm đi ra này và trên cơ hình lê và thường tập trung ở phần giữa haiphần ba của đường nối từ gai chậu sau trên đến mấu chuyển lớn. Trên thực tế, các mốc này khó xác định trên xác lẫn trên bệnh nhân và thay đổi theo tư thế, do đó chúng tôi đề xuất nghiên cứu định vị mạch xuyên theo trục độ $(x, y)$ với mốc là gai chậu trước trên. Chúng tôi dùng CLVT đa lát cắt dựa vào hệ trục toạ độ xoy để khảo sát vị trí ra da của mạch xuyên động mạch mông trên nhằm kiểm định lại vị trí ra da của mạch xuyên trên xác và trên lâm sàng với 2 mục tiêu nghiên cứu:
- Các kích thước mạch xuyên động mạch mông trên ở người Việt trưởng thành trên CLVT 320 lát cắt

- Định vị mạch xuyên động mạch mông trên ra da trên CLVT 320 lát cắt.

\section{II. ĐỐI TƯỢNG VÀ PHƯƠNG PHÁP NGHIÊN CỨU}

2.1. Thiết kế nghiên cứu: mô tả lâm sàng không nhóm chứng

2.2. Đối tượng nghiên cứu. Chọn 10 bệnh nhân người Việt trưởng thànhtại phòng khám Đa KhoaHoàHảo, từtháng 01-02/2021. Các bệnh nhân này được chỉ định chụp CLVT 320 lát cắt có bơm thuốc cản quang để khảo sát bệnh lý các tạng, chúng tôi khảo sát hình ảnh nhánh xuyên động mạch mông trên.

Tiêu chuẩn nhận (1) Bệnh nhân người Việt trưởng thành trên 18 tuổi, (2) Chưa từng phấu thuật vùng bụng, mông ở 2 bên.

Tiêu chự̂n loại: bệnh nhân có vùng bụng, mông đã phẫu thuật trước đó, hoặc có biến dạng cấu trúc mạch máu vùng này do ghép mạch, nối mạch haymắc bệnh lýbẩm sinh v.v..

2.3. Phương tiện nghiên cứu. Máy $C T$ Toshiba320 lát cắt và trạm xử lý hình ảnh VitreaA version 6.3.2160.184

2.4. Phương pháp nghiên cứu. Thuốc cản quang bơm liều $1,5-2 \mathrm{~mL} / \mathrm{kg}$, độ dày lát cắt $0,5 \mathrm{~mm}$ chồng lấn hình 0,2 . Xác định vị trí nhánh xuyên động mạch mông trênở 3 mặt phẳng qua phần mềm Vitrea trên trạm xử lý hình ảnh, đánh dấu mạch xuyên. Khảo sát nhánh xuyên động mạch mồng trên bằng cách xác định pha động mạch, rồi đánh dấu xác định đường đi mạch xuyên, đo đường kính, chiều dài và góc vào da. Thiết lập mốc gai chậu trước trên 2 bên để đo khoảng cách 2 gai chậu và định vị mạch xuyên ra da.

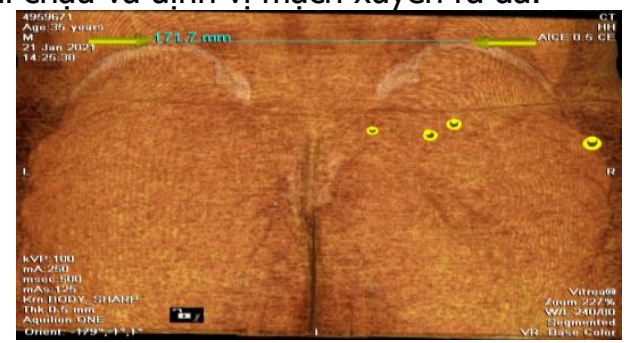

Hình 1. Định vị cácmạch xuyên động mạch mông trên theo truc toa độ

2.5. Các chỉ số cân thu thâap. Xác định số lượng mạch xuyên từ động mạch mông trên, đường đi, xác định điểm ra da mạch xuyên. Đo chiều dài, đường kính nguyên uỷ, ra da và góc vào da.

2.6. Phương pháp xử lý và phân tích số liệu. Mô tả, đo đạc các biến, thống kê tính toán 
các tỉ lệ, giá trị trung bình các biến số nghiên cứu, phân tích và xử lý các biến này bằng phép kiểm thống kê $\chi^{2}$ khi so sánh các tỉ lệ và t-test cặp đôi khi so sánh các giá trị trung bình giữa 2 bên bằng phần mềm SPSS/PC 21.0.

2.7. Vấn đề đạo đức. Bệnh nhân ký vào giấy đồng ý hợp tác nghiên cứu đã được thông qua hội đồng y đức trường.

\section{KẾT QUẢ NGHIÊN CỨU VÀ BÀN LUÂNN}

Chúng tôi khảo sát 10 vùng mông ở cả 2 bên phải trái trên hình ảnh CLVT 320 dãy gồm 5 nũ $(50 \%), 5$ nam (50\%) độ tuổi trung bình là 46 tuổi, cao nhất 73 tuổi, thấp nhất 30 tuổi.

\subsection{Các kích thướcmạch xuyên động mạch mông trên ở người Việt \\ 3.1.1. Nguồn gốc và số lượng mạch xuyên}

Trên hình ảnh CLVT 320 lát cắt, chúng tôi xác định ở mỗi bên phải và trái nhánh nông ĐM mông trên cho ra 4-5 mạch xuyên cơ ra da

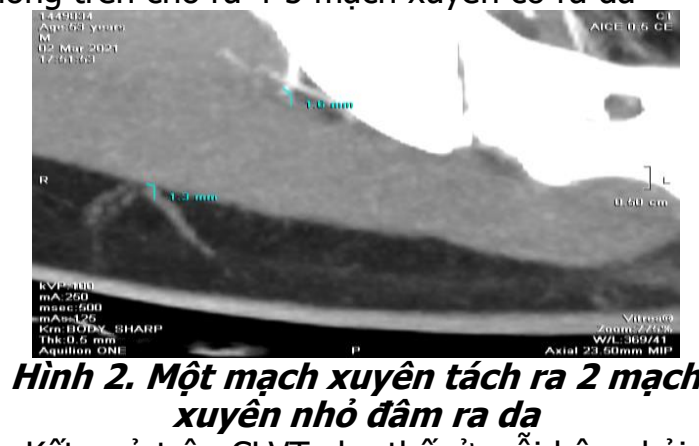

Kết quả trên CLVT cho thấyở mỗi bên phải và trái, nhánh nông ĐM mông trên cho ra 4-5 mạch xuyên cơ ra da, tương đồng với nghiên cứu Nguyễn Văn Thanh với số lượng nhánh xuyên động mạch mông trên trung bình là 6,3 nhánh (5-9 nhánh), trong đó số lượng nhánh xuyên là 6 nhánh chiếm tỉ lệ cao nhất $(56,7 \%)[8]$, hay Hoàng Minh Tú số nhánh xuyên trung bình trên mỗi tiêu bản là 4,3 nhánh, số nhánh xuyên động mạch mông trên theo giới tính và theo vị trí mổng trái và phải không có sự khác biệt nhau[7]. Kết quả này cũng phù hợp với Park H.J. trong một nghiên cứu trên người Hàn Quốc, số mạch xuyên trung bình khoảng 4,5 nhánh, hay Ahmadzadeh thực hiện trên thi thể[3], nhân đinh vùng mông trên được cấp máu bởi $5 \pm 2$ nhánh xuyên. Các nghiên cứu phẫu tích trên thi thể cho thấy số lượng và vị trí nhánh xuyên từ động mạch mông trên dao động lớn, trung bình số lượng nhánh xuyên lớn của động mạch mông trền được báo cáo khoảng 3 đến 5 (dao động từ 1 đến 7)[1], [2].

3.1.2. Loại mạch xuyên và hướng mạch xuyên vào da. Trên hình ảnh CLVTnhận thấy
$100 \%$ là nhánh xuyên cơ và đi trong cơ một đoạn khá dài trước khi đi vào da theo hướng chếch. Kết quả này cũng phù hợp với nghiên cứu trên xác của chúng tôi, thấy rằng dù là nhánh xuyên cơ hay xuyên vách thì các mạch xuyên luôn đi một đoạn trong cơ hay vách gian cơ trước khi đi vào da cấp máu. Do hướng đi chếch khá dài như vậy nên khi phẫu tích cuống mạch cũng dài theo, nhưng khi dùng vạt mạch xuyên động mạch mông trên để che phủ loét cùng cụt, do vị trí thiết kế vạt da thông thường nằm kế cận ổ loét, phẫu tích cuống mach xuyên trên bệnh nhân để xoay vạt che phủ ổ loét cũng không cần thiết cuống mạch xuyên dài, nên chỉ cần phẫu tích đến cơ mông lớn là đủ xoay để che phủ.

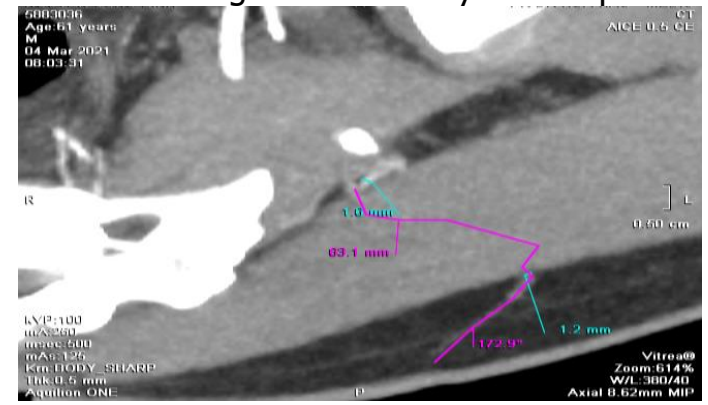

Hình 3. Nhánh xuyên đỉ chếch trong cơ môt đoan trước khi đí vào da

Kết quả này cũngphù hợp với Hashimoto I., [4] là các mạch xuyên nằm theo chiều dọc đi thẳng vào mồ nông trên cớ, các nhánh xuyên nằm dọc được ưa chuộng hơn vì chúng cho một cuống mạch máu dài hơn sau bóc tách nhánh xuyên và theo kinh nghiệm của tác giả cho thấy vạt mạch xuyên từ ĐM mông trên có thể được nầng lên thành một nhánh xuyên mà không sợ hoại tử vạt. Tương tự Granzow J.W., các nhánh xuyên nuôi dưỡng phần giữa mông đi trong cơ đoạn ngắn, trong khi các nhánh xuyên nuôi dưỡng phần bên phải đi trong cơ một đoạn chéo. Vì vậy, cuống dựa vào các nhánh xuyên từ phần bên ngoài của vùng da có khuynh hướng dài hơn so với từ các nhánh xuyên trong. Trái lại theo Vasilee J.V. và cộng sự, các nhánh xuyên đi ngang qua cơ mông lớn và cơ mông nhõ ở nhiều góc và khoảng cách khác nhau, nhánh xuyên đi qua các cơ mông lớn góc nhọn hơn, việc này có thể làm đường mổ ngắn hơn, tạo ra vạt có cuống chi phối bởi nhánh xuyên động mạch mông trên ngắn hơn về chiều dài $(6-8 \mathrm{~cm})$ [5].

Chúng tôi đồng ý với Tuinder S. nhận thấy đường đi mạch xuyên là yếu tố thứ phát ảnh hưởng đên sự lựa chọn nhánh xuyên, nếu hai mạch đều có kích thước giống nhau và cả hai có tính chất phân nhánh đều như nhau trong mô 
mõ dưới da, sau đó mạch được mổ dễ hơn, hay gây ít sang chấn cho cơ hơn sẽ được lựa chọn. Với cuống có chiều dài đủ cho việc che phủ thì một nhánh xuyên với đường đi trực tiếp vào cơ hợn sẽ được lựa chọn vì phẫu thuật sẽ dễ hơn, nhanh hơn và giảm tổn thương cho cơ mông lớn mặc dù trên lý thuyết mạch xuyên vách da có nhiều ưu thế hơn vì giảm chấn thương cơ mông lớn khi lấy vạt [1]. Theo chúng tôi, khi phẫu tích nhiều nhánh xuyên việc lựa chọn mạch xuyên nào giữ lại mạch xuyên nào bỏ hoàn toàn có thể dựa vào siêu âm Doppler mạch máu để chọn mạch nào có phổ âm lớn hơn.

Việc nghiên cứu hướng đi mạch xuyên để thiết kế vạt mông trên trong điêu trị loét cùng cụt theo chúng tôi không quan trọng cho lắm vì hướng đi của mạch xuyên sẽ ảnh hưởng đến chiêu dài cuống mạch, mà vạt mạch xuyên động mạch mông trên còn nhiều ứng dụng trong phẫu thuật tạo hình nhất là tạo hình vú sau ung thư. Do đó việc phẫu tích mạch xuyên sẽ đơn giản hơn khi ứng dụng che phủ ổ loét cùng cụt, nhận định này của chúng tôi phù hợp với Guerraa A.B. là hình dạng vạt da có thể được điều chỉnh bất kỳ hướng nào, miễn sao nhánh xuyên động mạch nằm trong vùng đó, cần chú ý vị trí của vạt da nằm hướng ngang với trục dài của vạt da sẽ tạo ra các cuống mạch máu dài hơn.

3.1.3. Các kích thước mạch xuyên. Trên CLVT, chúng tôi thu thập được tổng số 43 mạch xuyên bên phải, 42 mạch xuyên bên trái và thống kê các kích thước trung bình mạch xuyên theo bảng sau:

Bảng 1. Các kích thước mạch xuyên trên
CLVT
\begin{tabular}{|c|c|c|c|}
\hline $\begin{array}{c}\text { Kích thước mạch } \\
\text { xuyên (mm) }\end{array}$ & $\begin{array}{c}\text { Phải } \\
(\mathrm{n}=43)\end{array}$ & $\begin{array}{c}\text { Trái } \\
(\mathrm{n}=42)\end{array}$ & $\begin{array}{c}\text { p- } \\
\text { values }\end{array}$ \\
\hline Đường kính gốc & $1,5 \pm 0,2$ & $1,6 \pm 0,2$ & 0,551 \\
\hline Đường kính vào da & $1,1 \pm 0,2$ & $1,1 \pm 0,2$ & 0,490 \\
\hline Chiêu dài tữ nguyên & $62,0 \pm$ & $67,8 \pm$ & 0,015 \\
uỷ đến điểm ra da & 12,3 & 16,0 & 0,015 \\
\hline Góc vào da & 160,7 & 160,9 & 0,726 \\
\hline
\end{tabular}

$$
\begin{array}{|l|l|} 
\pm 18,3 & \pm 14,0
\end{array}
$$

Nhận xét: chiều dài mạch xuyên từ nguyên uỷ đến điểm ra da trung bình $6 \mathrm{~cm}$, không giống nhau giữa 2 bên phải và trái. Đường kính gốc mạch xuyên khá lớn $1,5 \mathrm{~mm}$ và vào da trên $1 \mathrm{~mm}$, góc vào da mạch xuyên trên CLVT đi khá chếch.

Trên CLVT là đường kính gốc mạch xuyên trung bình $1,5 \mathrm{~mm} v a ̀$ vào da cũng trên $1 \mathrm{~mm}$, góc vào da của mạch xuyên trên CLVT đi khá chếch; chiều dài mạch xuyên từ nguyên uỷ đến điểm ra da trung bình $6 \mathrm{~cm}$, không giống nhau giữa 2 bên phải và trái. Kết quả này phù hợp với Nguyễn Văn Thanh, đường kính gốc nhánh xuyên là $1,2 \mathrm{~mm}(0,8-1,6 \mathrm{~mm})$, trong đó số lượng mạch xuyên có đường kính $1,0-1,2 \mathrm{~mm}$ chiếm tî lệ cao nhất $(42,9 \%)$; chiêu dài nhánh xuyên là $42 \mathrm{~mm}$ (22-62mm), chiều dài từ da đến nguyên uỷ trung bình là $10,2 \mathrm{~cm}[8]$, nhưng lại nhỏ hơn đường kính nhánh xuyên của Hoàng Minh Tú là 2,2mm $(0,6-$ $4,6 \mathrm{~mm})$, chiều dài nhánh xuyên đoạn trong cơ là $72,4 \mathrm{~mm}$, đoạn ngoài cơ là $38,4 \mathrm{~mm}$ [7]. Sự khác biệt này có thể do mẫu nghiên cứu khác nhau, nhưng nhìn chung là tương tự không khác biệt nhiêu. Khá phù hợp với các tác giả nước ngoài như Ahmadzadeh, đường kính các nhánh xuyên từ $0,6-1,0 \mathrm{~mm}$ và chiều dài cuống trung bình từ cân sâu là 2,3 $21,1 \mathrm{~m}$ [3];Tansatit, đường kính ngoài nhánh xuyên từ $0,5-1,7 \mathrm{~mm}$ (trung bình $1,2 \mathrm{~mm})$, độ dài cuống tính tữ da tới động mạch chính khoảng 3-11,5cm (trung bình 5,9cm) [2].

Theo Vasile J.V. cho rằng các yếu tố tiên quyết cho nhánh xuyên tối ưu ở nền vạt là kích thước mạch, chiều dài cuống, vị trí mạch vào vạt, và các tính chất phân nhánh mạch máu trong vạt dưới da. Mạch máu càng lớn, chiều dài cuống đủ cho việc ghép vạt, vị trí trung tâm của mạch máu trên vạt và tính chất phân nhánh mạch máu dẫn đến sự tưới máu mô được ghép đều được ưu thích[5]. Từ kết quả này, chúng tôi thây đường kính và chiều dài mạch xuyên động mạch mông trên là một ưu điểm khi sử dụng vạt này và phù hợp với các tác giả khác.

\section{2. Định vị ra da mạch xuyên của động mạch mông trên ra da trên CLVT} Bảng 2. Ti lệ toạ độ mạch xuyên ra da động mạch mông trên

\begin{tabular}{|c|c|c|c|c|c|}
\hline Mạch & Bên & Tỉ lệ toạ độ x & p-values & Tỉ lệ toạ độ y & p-values \\
\hline \multirow{2}{*}{ xuyên 1} & phải & $0,4 \pm 0,1$ & \multirow{2}{*}{0,523} & $0,5 \pm 0,1$ & \multirow{2}{*}{0,017} \\
\hline & trái & $0,4 \pm 0,1$ & & $0,4 \pm 0,1$ & \\
\hline \multirow{2}{*}{ xuyên 2} & phải & $0,5 \pm 0,1$ & \multirow{2}{*}{0,340} & $0,5 \pm 0,1$ & \multirow{2}{*}{0,372} \\
\hline & trái & $0,5 \pm 0,0$ & & $0,5 \pm 0,1$ & \\
\hline \multirow{2}{*}{ xuyên 3} & phải & $0,5 \pm 0,0$ & \multirow{2}{*}{0,524} & $0,5 \pm 0,1$ & \multirow{2}{*}{0,269} \\
\hline & trái & $0,5 \pm 0,1$ & & $0,4 \pm 0,1$ & \\
\hline \multirow{2}{*}{ xuyên 4} & phải & $0,7 \pm 0,1$ & \multirow{2}{*}{0,189} & $0,5 \pm 0,1$ & \multirow{2}{*}{0,161} \\
\hline & trái & $0,7 \pm 0,1$ & & $0,5 \pm 0,2$ & \\
\hline
\end{tabular}


Nhận xét: chúng tôi nhận thây các mach xuyên tập trung từ khoảng 2/5 đến khoảng 3,5/5 trên trục $x$ và trên trục $y$ các mạch xuyên tập trung từ khoảng $2 / 5$ đến khoảng $2,5 / 5$. Sư phẩn bố mạch xuyên theo tỉ lệ 2 bên phải và trái không có sự khác biệt có ý nghĩa thống kê.

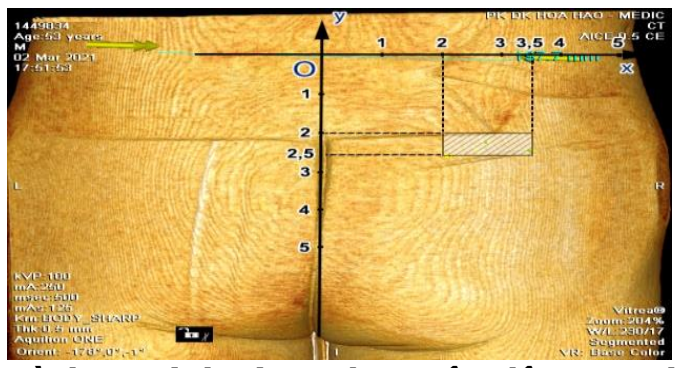

Hình 4. Định vỉ mach xuyên đông mach mông trên theo khoảng 5 trên CLVT

Chúng tôi định vị trí mạch xuyên trên CLVT theo khoảng 5 như sau: (1) Trục $x$ (từ gốc 0 sang hai gai châu trước trên): với trục $x$ ở mỗi bên chia đều thành 5 khoảng (từ khoảng 1 gần gốc 0 đến khoảng 5 xa gốc 0 sang 2 bên), vùng tập trung mach xuyên khoảng $2 / 5$ đến khoảng $3 / 5$ với tâm là giữa khoảng, (2) Trục y (từ gốc 0 đi xuống chấm dứt đường gian mông): với trục y chia thành 5 khoảng (từ khoảng 1 gân gốc 0 đến khoảng 5 xa gốc 0 hướng xuống dưới), vùng tập trung mạch xuyên khoảng $1,5 / 5$ đến khoảng $3,5 / 5$ với tâm là giữa khoảng); (3) Vùng tập trung mạch xuyên là hình chữ nhật theo chiều dọc dài $7 \mathrm{~cm}$ (2 khoảng 5$)$, chiều ngang $3,5 \mathrm{~cm}(1$ khoảng 5 ) với tâm là điểm giao giữa 2 đường thẳng đi qua giữa trục $x$ và giữa trục $y$ ở 2 bên; và hình chữ nhật này nằm trong tam giác trên chiếm diện tích nhiều hơn tam giác dưới.

Chúng tôi thấy để xác định vị trí 2 mốc mấu chuyển lớn xương đùi và gai chậu sau trên tương đối khó khăn nhất là trên bệnh nhân mập, nhiều mõ nhất là vùng mông, phù hợp theo nhận định của tác giả Kim và cộng sự nhận thấy vạt damông trên ở vùng trên trong gần gai chậu sau trên có độ dày mỏng nhất, vùng dày nhất là vùng trên ngoài gấp 3,24 lần vùng trên trong. Vat có khuynh hướng dày hơn theo hướng từ vùng mỏng trên trong đến vùng dưới trong hơn là vùng trên. Do đó chúng tôi đề xuất xây dựng hê trục toa 0 ngay tai điểm giữa 2 đường thẳng nối 2 gai châu trước trên ra sau (mốc dễ xác định trên người ốm lẫn người mập) (trục $x$ ) và đường thẳng từ 0 xuống đường gian mồng đến đỉnh xương cụt (trục y). Từ đó chúng tôi mapping mạch xuyên lên hệ trục toạ độ, nhân thây các mạch xuyên tập từ khoảng $2 / 5$ đến khoảng $3,5 / 5$ trên trục $x$ và trên trục $y$ các mạch xuyên tập trung từ khoảng $2 / 5$ đến khoảng $2,5 / 5$. Phát hiện quy luật phân bố mạch xuyên này của chúng tôi theo hình chữ nhật tương đối dễ thực hiện trên lâm sàng theo 5 khoảng và bô sung thêm khái niệm với các tác giả nghiên cứu trước đây mà kết quả vẫn phù hợp như theo Nguyễn Văn Thanh [8], vị trí trên da của nhánh xuyên động mạch mông trên phân bố trong đường tròn đường kính $6 \mathrm{~cm}$ có tâm là điểm $1 / 3$ trên ngoài đường nối từ gai chậu trước trên đến đỉnh xương cụt. So với các tác giả nước ngoài như Hallock G.G [6], kẻ một đường thẳng nối từ gai chậu sau trên đến xương cụt, và từ gai châu sau trền đến đỉnh mấu chuyển lớn. ở trung điểm đường nối từ gai châu sau trên đến xương cut, môt đường khác sẽ nối từ bờ trên của mấu chuyển lớn, đánh dấu một điểm ở một phần ba trong của đường nối từ gai chậu sau trên đến mấu chuyển lớn, nhánh xuyên chính của động mach mông trên sẽ tìm thấy ở phần ngang và phần xa của điểm đi ra này và trên cơ hình lê. Amadzadeh [3] cho rằng mạch xuyên họ tìm thấy tập trung ở phần giữa hai phần ba của đường nối từ gai chậu sau trên đến mấu chuyển lớn, tương tự cách vẽ và xác định trên, tác giả Gagnon A.R. vẽ hình chữ nhật theo trục mấu chuyển lớn xương đùi - gai chậu sau trên để định vị mạch xuyên, trong khi đó hình chữ nhật trong nghiên cứu chúng tôi theo trục toạ độ thẳng đứng. Cách chúng tôi, xác suất xác định mạch xuyên động mạch mông trên cao hơn.

\section{KẾT LUẦN}

Trên hình ảnh CLVT 320 lát cắt, ở mỗi bên phải và trái nhánh nông ĐM mông trên cho ra 4-5 mạch xuyên cơ ra da và $100 \%$ là mạch xuyên cơ, chiều dài mạch xuyên từ nguyên uỷ đến điểm ra da trung bình $6 \mathrm{~cm}$, không giống nhau giữa 2 bên phải và trái, đường kính gốc mạch xuyên $1,5 \mathrm{~mm}$ và vào da là $1 \mathrm{~mm}$, góc vào da mạch xuyên đi khá chếch. Các mạch xuyên trên hình ảnh CLVT tập trung từ khoảng 2/5 đến khoảng 3,5/5 trên trục $x$ và trên trục y các mạch xuyên tập trung từ khoảng 2/5 đến khoảng 2,5/5.

\section{TÀI LIẸU THAM KHẢO}

1. TuinderS., Hulst R.V.D., Lobbes $M_{.}$, et al. (2013).Septocutaneous Gluteal Artery Perforator (Sc-GAP) Flap for Breast Reconstruction: How We Do It. Breast Reconstruction - Current Perspectives and State of the Art Techniques, 9: 135-160.

2. Tansatit T., Chokrungyaranon $P_{\text {., Sanguansit }}$ P., et al. (2008). Anatomical Study of the Superior Gluteal Artery Perforator (S-GAP) for Free Flap Havesting. J Med Assoc Thai, 91(8): 1244-1249.

3. Ahmadzadeh R., Bergeron L, Tang M., et al.(2007). The Superior and Inferior Gluteal Artery 
Perforator Flaps. Plast Reconstr Surg. 2007 Nov, 120(6): 1551-1556.

4. Hashimoto I., Abe $Y_{\text {., }}$ Ishida $S_{.,}$et al. (2016).Development of Skin Flaps for Reconstructive Surgery: Random Pattern Flap to Perforator Flap. The Journal of Medical Investigation, 63: 159-162.

5. Vasile J.V., Newman T., Rusch D.G., et al. (2009). Anatomic Imaging of Gluteal Perforator Flaps without Ionizing Radiation: Seeing Is Believing with Magnetic Resonance Angiography. J Reconstr Microsurg. 2010 Jan, 26(1): 45-57.
6. Hallock G.G. (2009). A Primer of Schematics to Facilitate the Design of the Preferred Muscle Perforator Flaps.Plast Reconstr Surg. 2009 Mar, 123(3):1107-1015.

7. Hoàng Minh Tú (2020). Nghiên cứu giải phẫu nhánh xuyên động mach mông trên ở người Việt Nam, Luận án Tiến sĩ Y họ.

8. Nguyển Văn Thanh(2018). N Nghiên cứu vạt nhánh xuyên đông mach mông trên kết hợp hút áp lực âm trong điều trị vết loét mạn tính cung cut, Luận án Tiến sĩ Y học.

\section{ĐÁNH GIÁ KẾT QUẢ LÀM MỎNG THÌ ĐẦU VẠT ĐÙI TRƯớC NGOÀI TRONG PHẪU THUÂTT TẠO HÌNH}

\section{TÓM TẮT}

Mục tiêu nhằm đánh giá kết quả làm mỏng thì đầu vat đùi trước ngoài trong phẫu thuât tao hình. Nghiên cứu thực hiện trên 24 bệnh nhân với tổn khuyết được tao hình che phủ bằng vat đùi trước ngoài (ĐTN) làm mỏng thì đầu tại khoa Phẫu thuật tạo hình- Bệnh viện Xanh Pôn và khoa Phấu thuât tao hình - Bểnh viển Bạch Mai từ 01/2017 đến 08/2021. Trong đó, 23/28 vat $(82.14 \%)$ làm mỏng sơ cấp lấy bỏ lớp cân mõ sâu sử dụng kéo Mayo và 5/28 vạt (17.86\%) làm mỏng vi phẫu tích dưới kính hiển vi phấu thuật lấy bỏ thêm một phân lớp mõ̃ nông. Đảo cân mỡ quanh mạch xuyên kích thước nhỏ nhất $1.5 \times 1.5 \mathrm{~cm}$. Kết quả vạt sống hoàn toàn $26 / 28$ vạt $(92.86 \%)$, vạt thiểu dưỡng hoại tử một phần $2 / 28$ vạt (7.14\%), diện tích trung bình vat làm mỏng là $139.11 \pm 67.95 \mathrm{~cm}^{2}$, vat lớn nhất được làm mỏng có kích thước $322 \mathrm{~cm}^{2}$, độ dày trung bình vạt sau làm mỏng $0.49 \pm 0.12 \mathrm{~cm}$, vạt mỏng nhất thu được dày $0.3 \mathrm{~cm}$. Kết quả gần vạt che phủ tốt, liền thương tốt, kết quả xa bênh nhân hài lòng về mắt thẩm mỹ và chức năng. Như vậy vạt ĐTN làm mỏng thì đâu có thể được sữ dụng linh họat, an toàn, hiệu quả trong tạo hình che phủ tổn khuyết ở nhiều vùng trên cơ thể đặc biệt những vùng cần độ mỏng để đảm bảo chức năng và tính thẩm mỹ.

Tư khóa: Vạt đùi trước ngoài, làm mỏng sơ cấp, làm mỏng vi phẫu tích, vạt mạch xuyên.

\section{SUMMARY}

\section{ASSESSEMENT OF THE RESULT OF PRIMARY AND MICRODISECTION THINNING ANTEROLATERAL THIGH FLAP IN PLASTIC SURGERY}

Objective of this paper aims to evaluate the result of thinning the anterolateral thigh flap in plastic

*Trường Đại hoc Y Hà Nội

Chịu trách nhiệm chính: Nguyễn Ngọc Tuấn

Email: z29ftth@gmail.com

Ngày nhận bài: 2/8/2021

Ngày phản biên khoa hoc: 27/8/2021

Ngày duyệt bài: 20/9/2021
Trần Thiết Sơn*, Nguyễn Ngọc Tuấn*, Phạm Thị Việt Dung*, Tạ Thị Hồng Thuý* surgery. The study was carried out on 24 patients who underwent ALT flap thinning at the Department of Plastic surgery of Saint Paul Hospital and Bach Mai Hospital between January 2017 to August 2021. Primary thinning was performed on 23 out of 28 flaps $(82.14 \%)$ to remove the deep adipose tissue with Mayo scissors and microdissected thinning by microscopy was performed on the remaining 5 flaps $(17.86 \%)$ to remove an extra part of superficial adipose tissue. ALT thinning flap was harvested with $1.5 \times 1.5 \mathrm{~cm}$ of minimal deep fascial spared. Complete flap survival in 26 out of 28 flaps $(92.86 \%)$, partial flap necrosis in the remaining 2 flaps $(7.14 \%)$; average flap thinning area was $139.11 \pm 67.95 \mathrm{~cm}^{2}$, the largest flap was $322 \mathrm{~cm}^{2}$, the average flap thickness after thinning was $0.49 \pm 0.12 \mathrm{~cm}$, the thinnest flap obtained was $0.3 \mathrm{~cm}$. The short term result showed flaps with good coverage and good healing. Moreover, patients were satisfied with aesthetic and functional results in long-term follow-ups. In conclusion, the primary or microdissection ALT flap can be used multipurposely, safely, and effectively in plastic surgery to cover defects in various areas that need thinned flaps to improve functional and aesthetic results.

Keyword: Anterolateral flap, primary thinning, microdissection thinning, perforator flap.

\section{I. ĐăT VẤN ĐỀ}

Năm 1984, lần đầu tiên Song Y.G và cộng sự thông báo nghiên cứu về giải phẫu của vạt đừi trước ngoài (Anterolateral thigh Flap- ALT Flap) như là môt vat da cân có thể dùng với kỹ thuật vi phẫu. Kể từ đó đến nay, với những ưu điểm nổi bật của vạt này như: cuống mạch dài, tương đối hằng định về giải phẫu, đường kính lớn, vị trí cho vạt thuận lợi, vạt có thể lấy được kích thước lớn, vạt có thần kinh cảm giác, nơi cho vạt ít ảnh hưởng đến chức năng và thẩm mỹ $\tilde{y}^{1,2}$, nên vạt ĐTN đã trở thành 1 vạt da được sử dụng phổ biến nhất bởi tất cả các nhà tạo hình với nhiều mục đích khác nhau, nhiều vị trí khác nhau trên 